\title{
Src Potentiation of NMDA Receptors in Hippocampal and Spinal Neurons Is Not Mediated by Reducing Zinc Inhibition
}

\author{
Zhi-gang Xiong, ${ }^{1}$ Kenneth A. Pelkey, ${ }^{1,2}$ Wei Yang Lu, ${ }^{1}$ You Ming Lu, ${ }^{3}$ John C. Roder, ${ }^{3}$ John F. MacDonald, \\ and Michael W. Salter ${ }^{1,2}$ \\ ${ }^{1}$ Department of Physiology, ${ }^{2}$ Programme in Brain and Behavior, Hospital for Sick Children, and ${ }^{3}$ Samuel Lunenfeld \\ Research Institute, Mount Sinai Hospital, and Department of Molecular and Medical Genetics, University of Toronto, \\ Toronto, Ontario, Canada M5G 1 X8
}

\begin{abstract}
The protein-tyrosine kinase Src is known to potentiate the function of NMDA receptors, which is necessary for the induction of long-term potentiation in the hippocampus. With recombinant receptors composed of NR1-1a/NR2A or NR1-1a/2B subunits, Src reduces voltage-independent inhibition by the divalent cation $\mathrm{Zn}^{2+}$. Thereby the function of recombinant NMDA receptors is potentiated by Src only when the $\mathrm{Zn}^{2+}$ level is sufficient to cause tonic inhibition. Here we investigated whether the Src-induced potentiation of NMDA receptor function in neurons is caused by reducing voltage-independent $\mathrm{Zn}^{2+}$ inhibition. Whereas chelating extracellular $\mathrm{Zn}^{2+}$ blocked the Src-induced potentiation of NR1-1a/2A receptors, we found that $\mathrm{Zn}^{2+}$ chelation did not affect the potentiation of NMDA
\end{abstract}

The tyrosine kinase Src has been identified as an endogenous kinase responsible for upregulating activity of NMDA channels (Yu et al., 1997). The upregulation of NMDA receptors (NMDARs) by Src is necessary for the induction of long-term potentiation at Schaffer collateral synapses onto CA1 hippocampal neurons (Y. M. Lu et al., 1998). Also, Src permits enhancement of NMDAR function by intracellular $\mathrm{Na}^{+}$(Yu and Salter, 1998), and Src mediates the upregulation of NMDARs by PKC (Lu et al., 1999). Thus, Src may be a key point for various signaling pathways that regulate NMDAR function.

Regulation of NMDARs by Src has been studied using recombinant NMDARs expressed heterologously (Chen and Leonard, 1996; Kohr and Seeburg, 1996; Zheng et al., 1998). With receptors composed of NR1-1a and NR2A subunits, NMDAR currents are potentiated by Src, and this potentiation is occluded by chelating extracellular $\mathrm{Zn}^{2+}$ (Zheng et al., 1998). $\mathrm{Zn}^{2+}$ inhibits NMDARs by acting at a voltage-independent extracellular site and at a voltage-dependent site within the channel pore (Mayer et al., 1989). The voltage-independent site on NR1-1a/2A receptors has high affinity for $\mathrm{Zn}^{2+}$ causing tonic inhibition at $\mathrm{Zn}^{2+}$ concentrations normally contaminating extracellular solutions (Paoletti et al., 1997). Src causes a rightward shift in the $\left[\mathrm{Zn}^{2+}\right]-$

Received July 26, 1999; revised Aug. 23, 1999; accepted Sept. 7, 1999.

This work was supported by the Medical Research Council of Canada (Z.-g.X., Y.M.L., J.C.R., J.F.M., and M.W.S.), the Heart and Stroke Foundation of Canada (W.Y.L.) and the Savoy Foundation (K.A.P.). We thank Y. T. Wang for helpful comments on this manuscript and J. L. Hicks for preparing and maintaining dorsal horn cultures.

Z.-g.X. and K.A.P. contributed equally to this work.

Correspondence should be addressed to Michael W. Salter, Programme in Brain and Behavior, The Hospital for Sick Children, 555 University Avenue, Toronto, Ontario, Canada M5G 1X8. E-mail: mike.salter@utoronto.ca.

Copyright (C) 1999 Society for Neuroscience $0270-6474 / 99 / 190001-\bullet \$ 05.00 / 0$ receptor (NMDAR) currents by Src applied into hippocampal CA1 or CA3 neurons. Moreover, Src did not alter the $\mathrm{Zn}^{2+}$ concentration-inhibition relationship for NMDAR currents in CA1 or CA3 neurons. Also, chelating extracellular $\mathrm{Zn}^{2+}$ did not prevent the upregulation of NMDA single-channel activity by endogenous Src in membrane patches from spinal dorsal horn neurons. Taking these results together we conclude that Srcinduced potentiation of NMDAR currents is not mediated by reducing $\mathrm{Zn}^{2+}$ inhibition in hippocampal and dorsal horn neurons.

Key words: NMDA; Src; Zinc; hippocampus; spinal dorsal horn; EDTA

inhibition relationship for NR1-1a/2A receptors. Recombinant NMDARs composed of other subunits also show voltageindependent $\mathrm{Zn}^{2+}$ inhibition but have lower affinity for $\mathrm{Zn}^{2+}$. With NR1-1a/2B receptors Src does not potentiate NMDAR currents (Kohr and Seeburg, 1996), but these currents are not tonically inhibited by contaminating $\mathrm{Zn}^{2+}$. However, Src does produce a rightward shift in the $\left[\mathrm{Zn}^{2+}\right]$-inhibition relationship of NR1-1a/2B receptors (Zheng et al., 1998). Thus, a logical unifying concept is that Src reduces voltage-independent $\mathrm{Zn}^{2+}$ inhibition of NMDARs. A corollary to this is that for Src to potentiate NMDAR currents, $\left[\mathrm{Zn}^{2+}\right]$ must be matched to the $\mathrm{Zn}^{2+}$ sensitivity of the particular receptors tested so that there is tonic inhibition.

NMDARs in neurons exhibit voltage-independent inhibition by $\mathrm{Zn}^{2+}$ but have a lower $\mathrm{Zn}^{2+}$ sensitivity than do NR1-1a/2A receptors (Westbrook and Mayer, 1987). Because neuronal NMDAR currents are known to be potentiated by Src (Wang and Salter, 1994), we questioned whether Src enhances the function of native NMDARs by reducing $\mathrm{Zn}^{2+}$ inhibition. We report here

This article is published in The Journal of Neuroscience, Rapid Communications Section, which publishes brief, peerreviewed papers online, not in print. Rapid Communications are posted online approximately one month earlier than they would appear if printed. They are listed in the Table of Contents of the next open issue of JNeurosci. Cite this article as: JNeurosci, 1999, 19:RC37 (1-6). The publication date is the date of posting online at www.jneurosci.org.

http://www.jneurosci.org/cgi/content/full/3639 
Figure 1. Chelation of extracellular $\mathrm{Zn}^{2+}$ does not affect potentiation of NMDAR currents by Src in CA1 neurons but prevents potentiation with NR1-1a/2A receptors. $A$, Representative traces of NMDA-evoked currents from three neurons. Top traces, Currents before (Control) and $10 \mathrm{~min}$ after starting intracellular application of Src. Middle traces, Currents before and during bath application of EDTA $(10 \mu \mathrm{M})$. Bottom traces, Currents before and 10 min after starting intracellular application of Src when EDTA $(10 \mu \mathrm{M})$ was in the extracellular solution $(+E D T A) . B$, Histogram showing averaged peak amplitudes of NMDAR currents for CA1 neurons and for recombinant NR1-1a/ NR2A receptors. Src was applied intracellularly without or with $(\mathrm{Src} / E D T A)$ EDTA in the extracellular solution. The amplitude of the currents $10 \mathrm{~min}$ after the start of Src application was normalized cell by cell to the control level. Also plotted are averaged NMDAR current amplitudes for CA1 neurons during bathapplied EDTA or TPEN normalized to control. Error bars indicate SEM. * $p<0.05$ vs control, Student's $t$ test.

that, for hippocampal and dorsal horn neurons, chelating $\mathrm{Zn}^{2+}$ does not affect Src-induced potentiation of NMDARs, nor does Src affect the concentration dependence of $\mathrm{Zn}^{2+}$ inhibition. Thus, in these neuronal types Src potentiation of NMDAR currents is independent of $\mathrm{Zn}^{2+}$.

\section{MATERIALS AND METHODS}

\section{Hippocampal neuron isolation}

Hippocampal neurons were isolated from acute slices as described (Lu et al., 1999). Briefly, 14- to 24-d-old male Wistar rats anesthetized with halothane were killed by decapitation. Hippocampi were removed and cut into $\sim 500 \mu \mathrm{m}$ slices. Slices were incubated in extracellular solution containing $0.3-0.5 \mathrm{mg} / \mathrm{ml}$ papain (Sigma, St. Louis, MO) for 20-30 min. After incubation with the enzyme, slices were kept in enzyme-free extracellular solution. The CA1 or CA3 region was dissected, and the cells were isolated by gentle teasing using glass pipettes. Electrophysiological recordings started $\sim 15$ min after dissociation.

\section{HEK293 cell culture and transfection}

HEK293 cells were maintained, transfected, and used as described (W. Y. Lu et al., 1998). Cells were grown in a mixture of minimum essential medium (MEM) with Earle's salts and L-glutamine with $10 \%$ fetal bovine serum (FBS). Cells were plated $\left(\sim 10^{6}\right.$ cells per $35 \mathrm{~mm}$ dish $)$ and transfected $24 \mathrm{hr}$ later with combinations of NR1-1a/NR2A (1:3 ratio). After transfection cells were cultured in the presence of $100 \mu \mathrm{M}$ DL-2-amino-5-phosphono-valeric acid and recorded 24-48 hr after transfection.

\section{Dorsal horn cell culture}

Primary cultures of spinal dorsal horn were prepared from fetal Wistar rats (embryonic day 17-18) (Salter and Hicks, 1994). Briefly, the spinal cord was removed from each fetus, and the dorsal half of the cord was dissected. Dorsal horn neurons were isolated and plated in MEM supplemented with $10 \%$ FBS, $10 \%$ heat-inactivated horse serum, and $1 \mathrm{U} / \mathrm{ml}$ insulin. Cultures were used 7-21 d after plating. Media and sera were from Life Technologies (Burlington, Ontario, Canada).

\section{Electrophysiology}

Whole-cell recordings. Methods for whole-cell recording are described by $\mathrm{Lu}$ et al. (1999). Cells were bathed in extracellular solution containing (in mM): $140 \mathrm{NaCl}, 5.4 \mathrm{KCl}, 1.3 \mathrm{CaCl}_{2}, 25 \mathrm{HEPES}, 33$ glucose, 0.003 glycine (0.01 glycine for HEK293 cells), and 0.001 tetrodotoxin, $\mathrm{pH}$ 7.3-7.4 (320-335 mOsm). Extracellular $\left[\mathrm{Zn}^{2+}\right]$ in the solution bathing the cultures was measured using a Perkin-Elmer (Emeryville, CA) 5000 flame atomic absorption spectrometer. Patch electrodes contained (in $\mathrm{mM}$ ): $140 \mathrm{CsmethylSO}_{4}$ or CsF, 10 HEPES, 11 EGTA, 2 tetraethylammonium chloride, $1 \mathrm{CaCl}_{2}, 2 \mathrm{~mm} \mathrm{MgCl}_{2}$ and $4 \mathrm{~K}_{2}$-ATP (pH 7.3, 300 mOsm). Recombinant purified Src (Upstate Biotechnology, Lake Placid, NY; $50 \mathrm{U} / \mathrm{ml}$ ) was applied by intracellular perfusion (Wang et al., 1994) or by including Src in the pipette solution and allowing it to diff use into

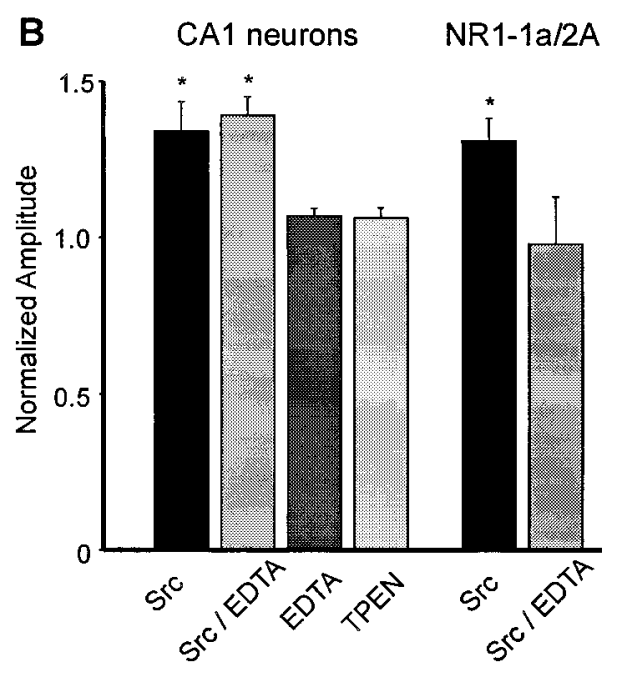

neurons after patch breakthrough. Whole-cell currents were recorded using Axopatch 1-D or Axopatch 200A amplifiers (Axon Instruments, Foster City, CA). Data were low-pass-filtered at $2 \mathrm{kHz}$ and acquired on a computer.

Membrane potential was held at $-60 \mathrm{mV}$ except where indicated. NMDA $(100 \mu \mathrm{M})$ was applied at 1 min intervals using a multibarrel, rapid perfusion system. Concentration-inhibition curves were fit with the logistic equation $I=I_{\max } /\left(1+\left(\left[\mathrm{Zn}^{2+}\right] / \mathrm{IC}_{50}\right)^{n}\right)$, where $I_{\max }$ is the current amplitude without $\mathrm{Zn}^{2+}$, and $n$ is the Hill coefficient.

Single-channel recordings. Single-channel recordings and analyses from inside-out patches are described by Wang et al. (1996). Cultures were bathed in extracellular solution containing (in mM): $110 \mathrm{Na}_{2} \mathrm{SO}_{4}, 10$ $\mathrm{Cs}_{2} \mathrm{SO}_{4}, 25 \mathrm{HEPES}, 1.3 \mathrm{CaCl}_{2}, 33$ glucose, 0.003 glycine, and 0.001 tetrodotoxin, $\mathrm{pH} 7.35$ (310-325 mOsm). NMDA channel activity was evoked by including $0.01 \mathrm{mM}$ NMDA in the extracellular solution in the patch pipettes. This solution was supplemented with EDTA (0.01 mM) as required. The solution bathing the intracellular aspect of the patches contained (in mM): $140 \mathrm{CsCl}, 10 \mathrm{HEPES}, 1 \mathrm{CaCl}_{2}, 10 \mathrm{BAPTA}, 2 \mathrm{MgCl}_{2}$, and $4 \mathrm{~K}_{2}$-ATP, pH 7.25 (310-325 mOsm), supplemented as required with the peptide EPQ(pY)EEIPIA (1 mm). Patches were held at $+70 \mathrm{mV}$, and current records were stored on tape. For analysis, recordings were replayed, filtered at $2 \mathrm{kHz}$, and sampled at $20 \mathrm{kHz}$ onto a computer. Channel openings and closings were determined using a $50 \%$ crossing threshold.

All electrophysiological experiments were done at room temperature $\left(22-24^{\circ} \mathrm{C}\right)$.

\section{RESULTS}

\section{Src enhances NMDA-activated currents in CA1 neurons when $\mathrm{Zn}^{2+}$ is chelated}

Src kinase was administered into CA1 neurons by intracellular perfusion after a 5-10 min control period during which NMDAevoked currents were stable. After perfusion with Src NMDAevoked currents gradually increased, and by $10 \mathrm{~min}$ of perfusion the currents had stabilized at $134 \pm 9.5 \%$ (mean \pm SEM) of the control level ( $n=5$ cells; Fig. 1$)$. We reasoned that if Src potentiates NMDAR currents by reducing $\mathrm{Zn}^{2+}$ inhibition, then NMDARs on CA1 neurons should be tonically inhibited by $\mathrm{Zn}^{2+}$. Therefore, decreasing free extracellular $\left[\mathrm{Zn}^{2+}\right]\left(\left[\mathrm{Zn}^{2+}\right]_{\mathrm{o}}\right)$ below the minimum level known to inhibit NMDAR function (Paoletti et al., 1997) would be predicted to increase NMDAR currents to the same degree as, or more than, administering Src. To reduce $\left[\mathrm{Zn}^{2+}\right]_{\mathrm{o}}$, cells were bathed in extracellular solution supplemented with the chelators EDTA $(10 \mu \mathrm{M})$ or $N, N, N^{\prime}, N^{\prime}$ tetrakis-(2-pyridylmethyl)-ethylene diamine (TPEN) (5 $\mu \mathrm{M})$. When EDTA or TPEN was included, NMDA-evoked currents were $107 \pm 3 \%(n=4$ cells $)$ and $106 \pm 3 \%(n=4$ cells $)$ of 

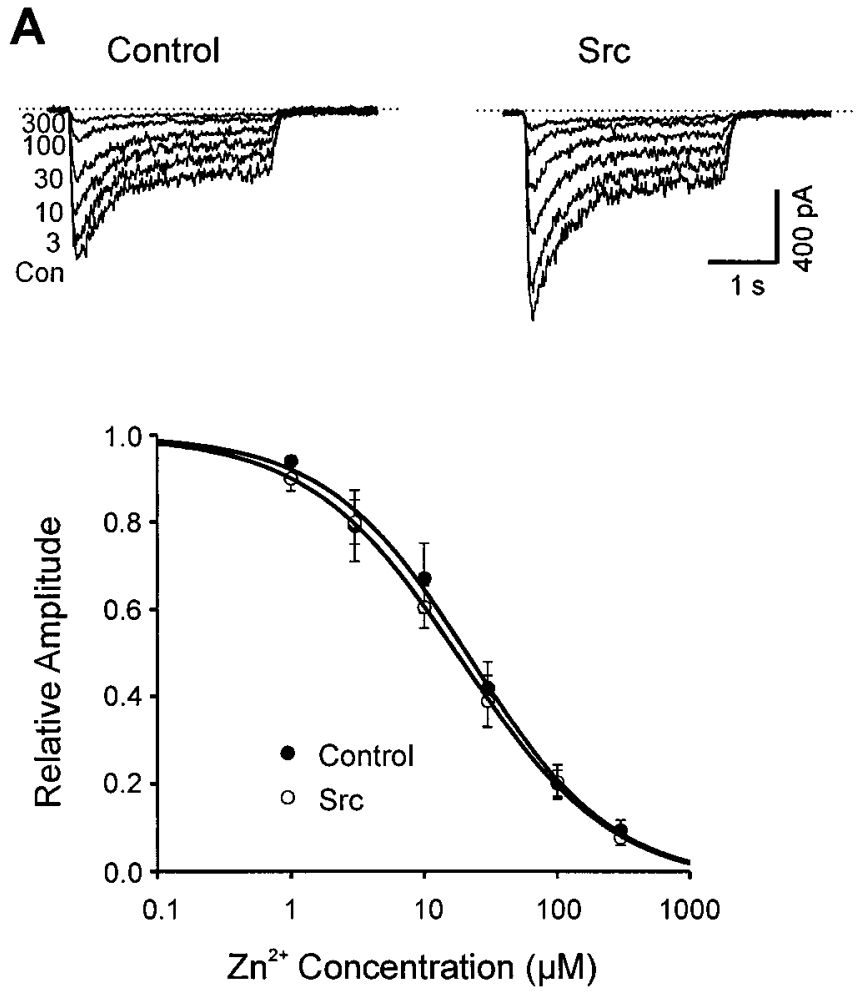

Figure 2. $\mathrm{Zn}^{2+}$ inhibition of NMDAR currents in CA1 neurons is unaffected by Src. A, Top panel, Superimposed traces from one neuron showing NMDA-evoked currents at varying $\left[\mathrm{Zn}^{2+}\right]_{\mathrm{o}}$ before (left) and during (right) intracellular application of Src. $\mathrm{Zn}^{2+}$ was present at the concentration indicated in both control and agonist-containing solutions. Bottom panel, $\left[\mathrm{Zn}^{2+}\right]$-inhibition relationship for peak NMDAR currents before ( $)$ or during (O) intracellular application of Src. Each point is the normalized amplitude averaged from five cells. The curves are the best fit of the average points to the logistic equations $1.02 /\left(1+\left(\left[\mathrm{Zn}^{2+}\right] / 22.0\right)^{0.80}\right)$ before Src and $1.03 /\left(1+\left(\left[\mathrm{Zn}^{2+}\right] / 18.8\right)^{0.76}\right)$ during Src. B, Top panel, I-V relation of NMDAR currents at the $\left[\mathrm{Zn}^{2+}\right]$ indicated. Currents taken during voltage ramps from -100 to $+60 \mathrm{mV}$ made during NMDA application were subtracted from currents without NMDA application. Bottom panel, Histogram showing averaged ratios $\left(I_{\text {zinc }} / I_{\text {control }}\right)$ of peak NMDAR current amplitude before versus during application of $\mathrm{Zn}^{2+}(10 \mu \mathrm{M})$ at the different membrane potentials indicated. The effect of $\mathrm{Zn}^{2+}$ was measured before (Control) or during Src administration ( $n=3$ cells in each group).

control, respectively. These levels were significantly less than that produced by administering $\operatorname{Src}(p<0.05$, Student's $t$ test $)$. To confirm that these concentrations of EDTA or TPEN would sufficiently lower $\left[\mathrm{Zn}^{2+}\right]_{\mathrm{o}}$, we measured $\left[\mathrm{Zn}^{2+}\right]$ in the extracellular solution by atomic absorption spectroscopy. $\left[\mathrm{Zn}^{2+}\right]_{\mathrm{o}}$ was found to be $170 \pm 40 \mathrm{~nm}(n=5$ samples each measured in duplicate). Using the known binding constants of EDTA and TPEN (Paoletti et al., 1997), we calculated that the chelators would decrease $\left[\mathrm{Zn}^{2+}\right]_{\mathrm{o}}$ to $<0.1 \mathrm{nM}$, which is below the minimum concentration of $\mathrm{Zn}^{2+}$ known to inhibit NMDAR currents (Paoletti et al., 1997). Hence, we conclude that tonic $\mathrm{Zn}^{2+}$ inhibition of NMDARs in CA1 neurons appears to be too small for its removal to account for the potentiation induced by Src.

If Src-induced potentiation of NMDAR currents in CA1 neurons is attributable to reducing tonic $\mathrm{Zn}^{2+}$ inhibition, then chelating extracellular $\mathrm{Zn}^{2+}$ should occlude the effect of Src. However, with EDTA $(10 \mu \mathrm{M})$ in the extracellular solution, applying Src intracellularly caused NMDAR currents to increase (Fig. $1 A$, bottom traces). On average NMDAR currents increased to $139 \pm$ $6.0 \%$ of control ( $n=4$ cells), which was not significantly different from the effect of Src in the absence of EDTA $(p>0.05$, Student's $t$ test). As a positive control for EDTA we examined its effect on Src-induced potentiation of NR1-1a/NR2A receptors expressed in HEK293 cells (Fig. 1B). When EDTA was not present, NR1-1a/2A currents increased to $131 \pm 7 \%$ of control ( $n=13$ cells, $p<0.01$ ) when Src was administered intracellularly.
On the other hand, when EDTA was present throughout the recording period NR1-1a/2A currents were $98 \pm 14 \%$ of control ( $n=12$ cells, $p>0.05$ ) when Src was applied. Therefore, as expected from the results of Zheng et al. (1998), EDTA prevented the potentiation of NR1-1a/2A currents by Src. Taking these results together, we conclude that the potentiation of NMDAR function in CA1 neurons is not dependent on extracellular $\mathrm{Zn}^{2+}$.

\section{Src does not affect the $\left[\mathrm{Zn}^{2+}\right]$ inhibition relationship in CA1 neurons}

Even though chelating $\mathrm{Zn}^{2+}$ did not prevent Src-induced potentiation of NMDAR currents, it is conceivable that Src might affect the concentration-inhibition relation for $\mathrm{Zn}^{2+}$. Therefore, we compared the concentration dependence of $\mathrm{Zn}^{2+}$ inhibition in dissociated CA1 neurons before and during Src application (Fig. $2 A$ ). Before applying Src, the $\mathrm{IC}_{50}$ for $\mathrm{Zn}^{2+}$ was $20 \pm 5 \mu \mathrm{M}$ $(n=5$; Fig. $2 A)$, which is similar to that reported previously for hippocampal neurons (Legendre and Westbrook, 1990). After Src perfusion the $\mathrm{IC}_{50}$ was $19 \pm 6 \mu \mathrm{M}(n=5$ cells; Fig. $2 A)$, which is not significantly different compared with before $\operatorname{Src}(p>0.05$, Student's $t$ test). Moreover, Src did not affect the Hill slope for the concentration-inhibition curve. Therefore, Src appeared to have no effect on the $\left[\mathrm{Zn}^{2+}\right]$-inhibition relationship of NMDARs in CA1 neurons. 


\section{$\mathrm{Zn}^{2+}$ inhibition unaffected by Src is voltage-independent}

Because Src did not affect $\mathrm{Zn}^{2+}$ inhibition of NMDAR currents in CA1 neurons, we considered it possible that the inhibition studied in these neurons was not the voltage-independent type, which Src reduces in recombinant receptors. Therefore, we examined the $I-V$ relationship of NMDA responses at various $\mathrm{Zn}^{2+}$ concentrations. With $\mathrm{Zn}^{2+}$ concentrations up to $30 \mu \mathrm{M}$ the $I-V$ relationship for NMDA-evoked currents was linear, indicating that up to this concentration $\mathrm{Zn}^{2+}$ acts at the voltageindependent site (Fig. 2B, top). Moreover, Src did not affect the inhibition by $\mathrm{Zn}^{2+}(10 \mu \mathrm{M})$ at membrane potentials between -80 and $+60 \mathrm{mV}$ (Fig. 2 B, bottom). Therefore, like the $\mathrm{Zn}^{2+}$ inhibition of recombinant receptors, the $\mathrm{Zn}^{2+}$ inhibition studied presently in CA1 neurons is voltage-independent. However, unlike the voltage-independent $\mathrm{Zn}^{2+}$ inhibition of recombinant receptors, this type of inhibition of NMDAR currents in CA1 neurons is unaffected by Src.

\section{Src enhancement of NMDAR currents in CA3 neurons is independent of extracellular $\mathrm{Zn}^{2+}$}

Although Src-induced potentiation of NMDA-evoked currents in CA1 neurons did not depend on $\mathrm{Zn}^{2+}$, there may be other neuronal populations in which this effect of Src is attributable to reducing $\mathrm{Zn}^{2+}$ inhibition. Because mossy fiber terminals in the CA3 region of the hippocampus have the highest level of releasable $\mathrm{Zn}^{2+}$ in the CNS (Frederickson, 1989), CA3 neurons are exposed to $\left[\mathrm{Zn}^{2+}\right]_{0}$ much higher than that experienced by CA1 neurons. Therefore, as a contrasting population of cells we tested neurons dissociated from CA3. In these experiments Src was administered by including it in the intracellular recording solution and allowing it to diff use into the neurons immediately after the whole-cell configuration was attained by rupturing the membrane patch (Fig. 3). Administering Src caused NMDAR currents to increase gradually to $160 \pm 23 \%$ of the initial level $(n=5$ cells $)$ within $10 \mathrm{~min}$ after patch rupture. In contrast, when heatinactivated Src was included in the recording pipette, NMDAR currents remained stable at the initial level throughout the recording period. Thus, Src kinase activity was required to potentiate NMDAR function in CA3 neurons.

To determine whether Src-induced potentiation requires $\mathrm{Zn}^{2+}$, experiments were done with EDTA in the extracellular solution. In these experiments, administering $\mathrm{Src}$ increased NMDAR currents to $153 \pm 31 \%$ of the initial level ( $n=5$ cells). This increase was not significantly different from that observed in the absence of EDTA ( $p>0.05$, Student's $t$ test). Furthermore, Src did not affect the $\left[\mathrm{Zn}^{2+}\right]$-inhibition relationship $\left(\mathrm{IC}_{50}, 15.4 \pm\right.$ $2.9 \mu \mathrm{M}$ before Src vs $13.0 \pm 2.5 \mu \mathrm{M}$ after Src; $p>0.05$, Student's $t$ test), and the inhibition was voltage-independent at the $\left[\mathrm{Zn}^{2+}\right]$ tested, up to $30 \mu \mathrm{M}$ (data not shown).

\section{Endogenous Src increases NMDA channel function when extracellular $\mathrm{Zn}^{2+}$ is chelated}

Endogenous Src kinase is known to associate with and upregulate the function of neuronal NMDARs (Yu et al., 1997). The regulation of NMDARs by endogenous Src has been best characterized by studying NMDA single-channel activity in inside-out patches excised from dorsal horn neurons. In these patches,
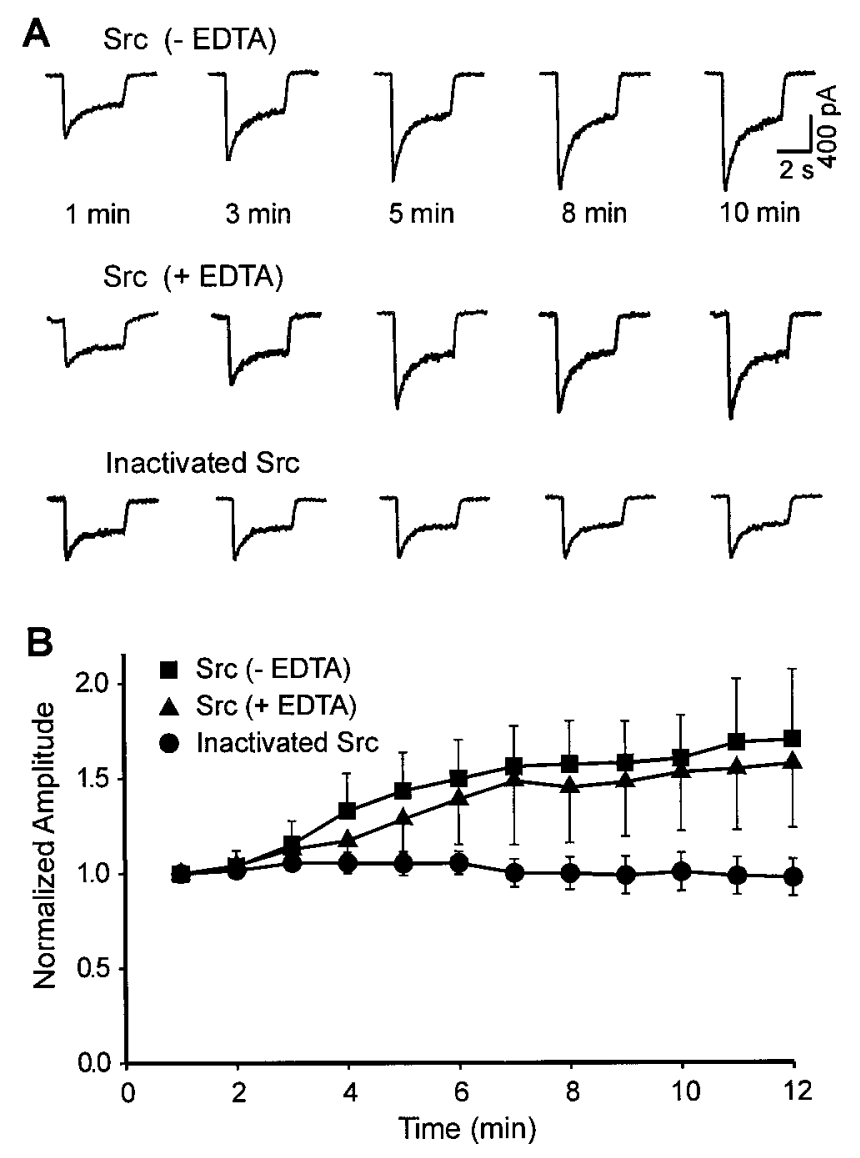

Figure 3. Chelation of extracellular $\mathrm{Zn}^{2+}$ fails to affect Src-induced potentiation of NMDAR currents in CA3 neurons. $A$, Traces from three cells showing NMDAR whole-cell currents evoked at the times indicated after patch breakthrough. Src was included in the intracellular solution for the top two cells, and heat-inactivated Src was included for the bottom cell. The extracellular solution was supplemented with EDTA $(10 \mu \mathrm{M})$ for the middle cell. $B$, Averaged peak NMDAR currents are plotted at $1 \mathrm{~min}$ intervals after patch rupture under the conditions indicated. Data are normalized with respect to the peak amplitude of the first response evoked after formation of the whole-cell configuration $(n=5$ for each group). $p>0.05$ for comparison between Src ( - EDTA) and Src (+ EDTA) by two-way ANOVA.

application of the phosphopeptide EPQ(pY)EEIPIA has been shown to enhance NMDA channel function through stimulating endogenous Src (Yu et al., 1997). Therefore, to determine whether the upregulation by endogenous Src depends on $\mathrm{Zn}^{2+}$, we used inside-out patches from dorsal horn neurons and applied EPQ(pY)EEIPIA to activate Src (Fig. 4). These experiments also allowed us to examine a neuronal population outside the hippocampus. We found that applying $\operatorname{EPQ}(\mathrm{pY}) \mathrm{EEIPIA}$ to the cytoplasmic face of the patches increased NMDA channel open probability $\left(P_{\mathrm{o}}\right)$ and mean open time $\left(t_{\mathrm{o}}\right)$ to $209 \pm 36$ and $135 \pm$ $11 \%$ of control, respectively ( $n=5$ patches). In recordings in which EDTA $(10 \mu \mathrm{M})$ was included in the pipette solution to chelate extracellular $\mathrm{Zn}^{2+}$, applying EPQ(pY)EEIPIA increased $P_{\mathrm{o}}$ and $t_{\mathrm{o}}$ to $214 \pm 51$ and $140 \pm 15 \%$ of control, respectively $(n=$ 6 patches). The increase in $P_{\mathrm{o}}$ and $t_{\mathrm{o}}$ induced by EPQ(pY)EEIPIA with EDTA was not significantly different from that without EDTA $(p>0.05$, Student's $t$ test $)$. Thus, the mechanism of NMDAR potentiation by endogenous Src in dorsal horn neurons is not reduction of $\mathrm{Zn}^{2+}$ inhibition. 

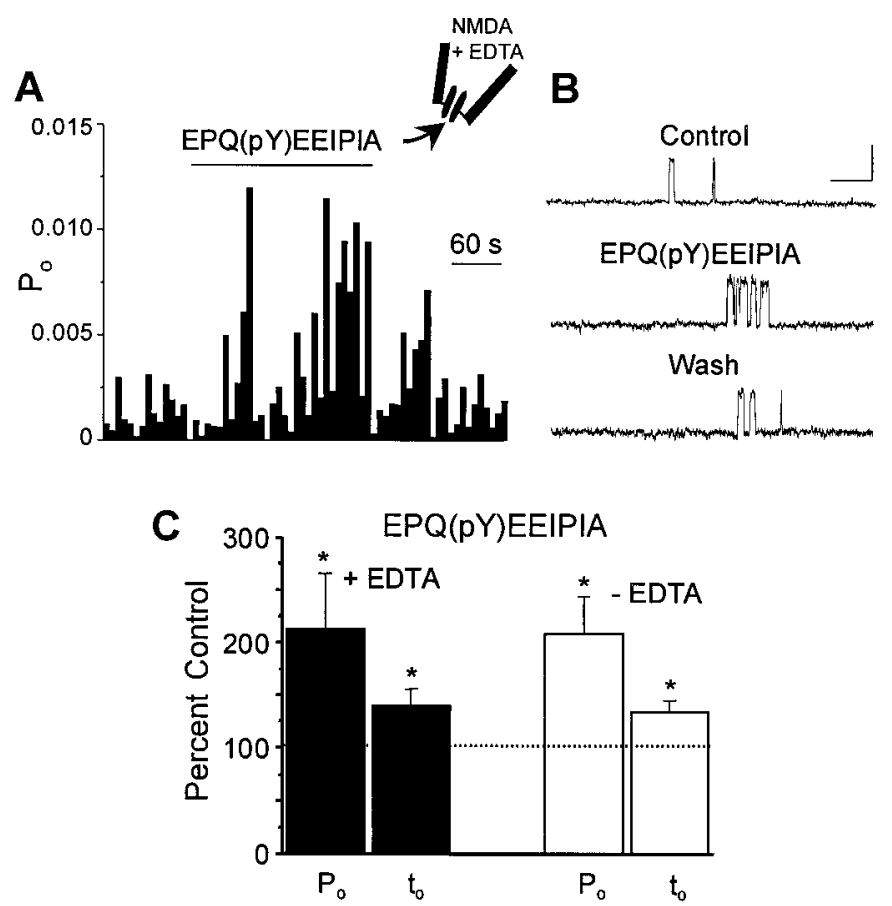

Figure 4. Upregulation of NMDAR activity by endogenous Src in dorsal horn neurons is unaffected by chelating extracellular $\mathrm{Zn}^{2+} . A$, Continuous-time histogram showing NMDA channel open probability $\left(P_{\mathrm{o}}\right)$ from an inside-out patch recording made with EDTA $(10 \mathrm{mM})$ in the pipette solution. The Src activator peptide EPQ(pY)EEIPIA (1 mM) was applied during the period indicated. $B$, Example current traces before, during, and after (Wash) EPQ(pY)EEIPIA application from the patch shown in $A$. Calibration: $3 \mathrm{pA}, 50 \mathrm{msec}$. $C$, Histogram showing averaged $P_{\mathrm{o}}$ or $t_{\mathrm{o}}$, calculated as percentage of control, during application of EPQ(pY)EEIPIA with $(+E D T A)$ and without $(-E D T A)$ EDTA in the pipette solution. ${ }^{*} p<0.05$, paired $t$ test before vs during EPQ(pY)EEIPIA.

\section{DISCUSSION}

In the present study we have found that the potentiation of NMDA-evoked currents by the protein-tyrosine kinase Src in CA1, CA3, and spinal dorsal horn neurons is unaffected by chelating extracellular $\mathrm{Zn}^{2+}$. Moreover, Src did not affect the concentration dependence of the inhibition of NMDAR currents by $\mathrm{Zn}^{2+}$. Taking these findings together, we must conclude that Src potentiation of NMDAR currents in the neuronal populations tested is not mediated by reducing $\mathrm{Zn}^{2+}$ inhibition.

In contrast, as reported previously (Zheng et al., 1998) and confirmed in the present study, Src potentiates the function of recombinant NMDARs by reduction of inhibition by $\mathrm{Zn}^{2+}$. The upregulation of recombinant NMDARs by Src is intriguing, because it links two modulatory sites of the NMDAR that had previously been considered independent and suggests that there must be a novel mechanism for transmitting the effect of phosphorylation from the inside of the membrane to the outside (Ascher, 1998). Although understanding this mechanism could provide interesting insights into NMDA channels, the relevance of this mechanism to neuronal function remains to be established. Our results do not exclude the possibility that there are neuronal populations in which this transmembrane mechanism is active. But we could find no evidence for this in the neurons tested, indicating clearly that Src is capable of working through a mechanism distinct from that described with the recombinant receptors tested.
Why are recombinant NMDA channels upregulated by Src differently from the native channels examined in the present study? One potential explanation might have been that Src did not have the opportunity to work through the same mechanism, because the type of $\mathrm{Zn}^{2+}$ inhibition in the neurons was different from that of the recombinant receptors. However, with both native and recombinant NMDARs the $\mathrm{Zn}^{2+}$ inhibition is voltage-independent: Src reduced this type of inhibition with the recombinant receptors but not with the native receptors. A second possible explanation may be that the subunit compositions of the recombinant receptors tested do not correspond to the native channels studied. The recombinant receptors were diheteromeric, comprising only one NR1 splice variant and one NR2 gene product. There is increasing evidence that native NMDARs may comprise more than just NR1 and a single type of NR2 subunit (Sheng et al., 1994; Chazot and Stephenson, 1997; Luo et al., 1997; Das et al., 1998), and such receptors could have properties that differ from those of diheteromeric receptors (Brimecombe et al., 1997). A third possible explanation may be that HEK293 cells do not express an NMDAR-associated protein required for the neuronal mechanism or that they express a non-neuronal protein that causes Src potentiation via a different mechanism.

Recently, it has been suggested that voltage-independent $\mathrm{Zn}^{2+}$ inhibition is via coupling to proton inhibition of NMDARs (Choi and Lipton, 1999). This suggestion highlights an emerging theme of convergence of modulatory sites on proton inhibition and raises the possibility that Src upregulation of NMDAR function might be caused by reducing proton inhibition. It is conceivable that, in neurons, the effect of tyrosine phosphorylation may not require negative coupling through the $\mathrm{Zn}^{2+}$ modulatory site, as apparently occurs with recombinant receptors, but might relieve proton inhibition directly.

In the CNS the ambient $\left[\mathrm{Zn}^{2+}\right]_{\mathrm{o}}$ may vary in different regions and under different circumstances (Smart et al., 1994). If the mechanism for Src potentiation in neurons was reducing $\mathrm{Zn}^{2+}$ inhibition, then a physiologically important consequence would be that Src potentiation of NMDAR synaptic responses would be permitted only where $\left[\mathrm{Zn}^{2+}\right]_{o}$ appropriately matched the $\mathrm{Zn}^{2+}$ sensitivity of synaptically activated NMDARs. However, our results indicate that in the hippocampus and the spinal dorsal horn potentiation of NMDAR synaptic transmission by Src will occur regardless of the $\mathrm{Zn}^{2+}$ level.

\section{REFERENCES}

Ascher P (1998) Zinc, Src and NMDA receptors-a transmembrane connection. Nat Neurosci 1:173-175.

Brimecombe JC, Boeckman FA, Aizenman E (1997) Functional consequences of NR2 subunit composition in single recombinant $N$-methylD-aspartate receptors. Proc Natl Acad Sci USA 94:11019-11024.

Chazot PL, Stephenson FA (1997) Molecular dissection of native mammalian forebrain NMDA receptors containing the NR1 C2 exon: direct demonstration of NMDA receptors comprising NR1, NR2A, and NR2B subunits within the same complex. J Neurochem 69:2138-2144.

Chen S-J, Leonard JP (1996) Protein tyrosine kinase-mediated potentiation of currents from cloned NMDA receptors. J Neurochem 67:194-200.

Choi YB, Lipton SA (1999) Identification and mechanism of action of two histidine residues underlying high-affinity $\mathrm{Zn} 2+$ inhibition of the NMDA receptor. Neuron 23:171-180.

Das S, Sasaki YF, Rothe T, Premkumar LS, Takasu M, Crandall JE, Dikkes P, Conner DA, Rayudu PV, Cheung W, Chen HS, Lipton SA, Nakanishi N (1998) Increased NMDA current and spine density in mice lacking the NMDA receptor subunit NR3A. Nature 393:377-381. 
Frederickson CJ (1989) Neurobiology of zinc and zinc-containing neurons. Int Rev Neurobiol 31:145-238.

Kohr G, Seeburg PH (1996) Subtype-specific regulation of recombinant NMDA receptor-channels by protein tyrosine kinases of the src family. J Physiol (Lond) 492:445-452.

Legendre P, Westbrook GL (1990) The inhibition of single $N$-methyl-Daspartate-activated channels by zinc ions on cultured rat neurones. J Physiol (Lond) 429:429-449.

Lu WY, Xiong ZG, Orser BA, MacDonald JF (1998) Multiple sites of action of neomycin, $\mathrm{Mg} 2+$ and spermine on the NMDA receptors of rat hippocampal CA1 pyramidal neurones. J Physiol (Lond) 512:29-46.

Lu WY, Xiong ZG, Lei S, Orser BA, Dudek E, Browning MD, MacDonald JF (1999) G-protein-coupled receptors act via protein kinase $\mathrm{C}$ and Src to regulate NMDA receptors. Nat Neurosci 2:331-338.

Lu YM, Roder JC, Davidow J, Salter MW (1998) Src activation in the induction of long-term potentiation in CA1 hippocampal neurons. Science 279:1363-1368.

Luo J, Wang Y, Yasuda RP, Dunah AW, Wolfe BB (1997) The majority of $N$-methyl-D-aspartate receptor complexes in adult rat cerebral cortex contain at least three different subunits (NR1/NR2A/NR2B). Mol Pharmacol 51:79-86.

Mayer ML, Vyklicky LJ, Westbrook GL (1989) Modulation of excitatory amino acid receptors by group IIB metal cations in cultured mouse hippocampal neurones. J Physiol (Lond) 415:329-350.

Paoletti P, Ascher P, Neyton J (1997) High-affinity zinc inhibition of NMDA NR1-NR2A receptors. J Neurosci 17:5711-5725.
Salter MW, Hicks JL (1994) ATP-evoked increases intracellular calcium in cultured neurones and glia from the dorsal spinal cord. J Neurosci 14:1563-1575.

Sheng M, Cummings J, Roldan LA, Jan YN, Jan LY (1994) Changing subunit composition of heteromeric NMDA receptors during development of rat cortex. Nature 368:144-147.

Smart TG, Xie X, Krishek BJ (1994) Modulation of inhibitory and excitatory amino acid receptor ion channels by zinc. Prog Neurobiol 42:393-441.

Wang LY, Dudek EM, Browning MD, MacDonald JF (1994) Modulation of AMPA/kainate receptors in cultured murine hippocampal neurones by protein kinase C. J Physiol (Lond) 475:431-437.

Wang YT, Salter MW (1994) Regulation of NMDA receptors by tyrosine kinases and phosphatases. Nature 369:233-235.

Wang YT, Yu XM, Salter MW (1996) Ca(2+)-independent reduction of $N$-methyl-D-aspartate channel activity by protein tyrosine phosphatase. Proc Natl Acad Sci USA 93:1721-1725.

Westbrook GL, Mayer ML (1987) Micromolar concentrations of Zn2+ antagonize NMDA and GABA responses of hippocampal neurons. Nature 328:640-643.

Yu X-M, Salter MW (1998) Gain control of NMDA-receptor currents by intracellular sodium. Nature 396:469-474.

Yu XM, Askalan R, Keil GJ, Salter MW (1997) NMDA channel regulation by channel-associated protein tyrosine kinase Src. Science 275:674-678.

Zheng F, Gingrich MB, Traynelis SF, Conn PJ (1998) Tyrosine kinase potentiates NMDA receptor currents by reducing tonic zinc inhibition. Nat Neurosci 1:195-191. 